\title{
Evaluating the effectiveness of a website about masculinity and suicide to prompt help-seeking
}

\author{
Kylie King*1 \\ Marisa Schlichthorst ${ }^{1}$ \\ Jackie Turnure \\ Andrea Phelps ${ }^{2}$ \\ Matthew J Spittal ${ }^{1}$ \\ Jane Pirkis ${ }^{1}$
}

* Corresponding author: k.king@unimelb.edu.au

1. Centre for Mental Health, Melbourne School of Population and Global Health, The University of Melbourne

2. Phoenix Australia, Centre for Posttraumatic Mental Health, The University of Melbourne.

Acknowledgements: The authors would like to thank the Movember Foundation for supporting the development and evaluation of Man Up. They would also like to thank Heiress Films for producing the documentary and associated social media campaign, and the Australian Broadcasting Corporation for screening the documentary. The authors are grateful to the Advisory Group that provided guidance at various critical stages in the project. They would also like to acknowledge Gus Worland and everyone else who appeared in the documentary.

\section{Competing interests: None}

Funding: Funding for Man Up was provided by the Movember Foundation. Funds supported the development of the documentary and associated social media campaign, as well as their evaluation. The Movember Foundation had no role in the design or conduct of the study reported here or in preparation of this manuscript. 


\section{Issue addressed}

A website was designed to form the core of a multimedia strategy surrounding the Man Up documentary - a three-part documentary that aimed to address the problem of male suicide in Australia. Together these formed a media-based, public health intervention that explored the link between masculinity and suicide and promoted help-seeking. This is of great importance given the demonstrated link between masculine norms, men's reduced help-seeking and suicidal thinking. This study assesses the website's effectiveness in facilitating help-seeking and fostering conversations about suicide, mental health, and help-seeking. Help-seeking indicators included website clicks to helping organisations, downloads of health information from the website, and request for help received via emails.

\section{Methods}

Google Analytics data, emails to the Man Up team received through the website, and open-ended responses to an online survey were analysed.

\section{Results}

The website reached 43,140 users. Indictors of help-seeking activity on the website included 307 outbound clicks to helping organisations and 802 downloads of health information. Qualitative analysis of emails received and responses to the survey demonstrated that Man Up's messages resonated with viewers and provided further evidence of help-seeking.

\section{Conclusion}

The findings demonstrate that the website provided an important opportunity for people to engage with Man Up and seek help.

\section{So what?}


Media-based public health interventions offer enormous potential to provide suicide prevention interventions and promote help-seeking. The website evaluation findings provide insight into the ways in which websites can be used as part of a multimedia strategy to address the problem of male suicide. 


\section{INTRODUCTION}

There are many websites that are designed to prevent suicide. The aims, content and target of these sites vary considerably. Websites can be classified using a quadrant taxonomy that categorises them across two domains that describe the way they provide content and opportunities for interaction: informative/educational to interventionist and passive to active/interactive. ${ }^{1}$ As part of the Man Up initiative we developed a passive-informative/educational website to accompany a television documentary series. The website acted to: promote the documentary; provide additional information and resources; further engage the audience in the key messages promoted in the documentary; and encourage help-seeking. The website specifically targeted men, because they are at particularly heightened risk of suicide (men account for three-quarters of all suicides annually in Australia ${ }^{2}$ ). Website content was premised on previous research that consistently demonstrates a link between traditional masculine norms and men's reduced help-seeking, negative psychological outcomes and suicidal thinking. ${ }^{34}$ The website can be found here www.manup.org.au.

The centrepiece of the Man Up initiative was a 3-part documentary series which follows a presenter (Gus Worland, Australian media personality) as he explores the relationship between masculinity and suicide. Gus travels around Australia talking to men from all walks of life trying to understand what is driving men's suicidal behaviour. These men help Gus to understand that masculine norms may encourage men to "bottle things up" and discourage them from reaching out to others. Importantly, they model positive behaviours such as talking about problems, expressing emotion and seeking help. The documentary design was based on the 
theory of planned behaviour. The theory proposes that behavioural intentions are influenced by attitudes towards behaviour, perceived behavioural control, and subjective norms. ${ }^{5}$ The documentary aimed to: demystify and normalise men's emotional experiences, emotional expression and help-seeking; challenge aspects of masculinity related to self-reliance; and provide positive role models for change.

The website formed the core of a broader digital strategy that accompanied the documentary. Website content included: trailers, television episodes (once broadcast) and additional short videos; statistics and resources (psychoeducation materials) about suicide; profiles of 37 men, including well-known celebrities from sports and entertainment and everyday men ranging from tradesmen to corporate high flyers, representing a diversity of masculinities (varying in age, cultural backgrounds, sexuality, occupations) talking about their life experiences (Real Aussie Blokes); research about masculinity presented in an accessible way using humour and colloquial language (Blokelore), such as reflections on how we raise our boys (Boys to Men), mateship (The mate test), and intimate relationships (How big is your organ); Gus's production blog; and links to helping organisations (Help A Mate). The website design and testing are described in another paper (reference removed for peer review).

Users could share website content directly through various social media channels and via email and could contact the Man Up team via a 'contact us' link. Emails were sent to a Gmail account that was set up for the project. There was also a brief survey on the website. The other element of the digital strategy was a social media campaign, delivered across five platforms (Twitter, Facebook, Instagram, YouTube 
and tumblr). Together the documentary, website and social media campaign formed a media-based, public health intervention that explored the link between masculinity and suicide and promoted help-seeking.

This paper describes our assessment of the website's reach and engagement, and its effectiveness in facilitating help-seeking and stimulating conversations about suicide, mental health and help-seeking. We were interested in indicators of helpseeking such as clicks on links to helping organisations, downloads of health information, and emails featuring suicide, mental health, and help-seeking related content. For the website to be effective in facilitating help-seeking it needed to first be effective in reaching users and engaging them in website site content. Therefore, we were also interested to know the reach of the website and the degree to which users engaged with it. We were also interested in the content of emails and the openended comments provided in the survey.

The paper focusses on website visits, emails and survey responses that occurred between 15 August and 20 November 2016. This time period includes the initial television screening of the documentary (11, 18 and 25 October), and the active period of the social media campaign that began in anticipation of the television screening on 15 August and was gradually wound down after 20 November. Openended survey responses were only available after the television screening (beginning 12 October), as these questions were not present in the survey pre-screening. These questions asked about respondents' views about the term 'Man Up' and for their 'other comments'. Our exploration of the website is part of a broader evaluation of the overall Man Up initiative. 


\section{METHOD}

We evaluated website effectiveness in relation to three research questions.

\section{How did the website perform in terms of overall reach and engagement?}

We used Google Analytics to evaluate the website in terms of attracting and engaging users. Google Analytics is a free website analytics service provided by Google that provides data related to website traffic via a series of reports available from an online dashboard. Google Analytics provides a range of data related to the way in which visitors engage with the website. ${ }^{67}$ Prior to the release of the website an enhanced Google Analytics account was created and configured, along with the website, to enable data tracking and collection, and provide custom reports. ${ }^{6}$ Our customised account set up enabled tracking of user paths throughout the site.

Data were collated from the Google Analytics dashboard in September 2017 for all website visits that occurred in the observation period (between 15 August and 20 November 2016). Table 1 describes the variables that were available through Google Analytics. We were unable to analyse data related to age and gender. The Google Analytics dashboard provides information related to users' age and gender, however the accuracy of this data has not yet been established. Gender and age are not collected directed by Google but are estimations obtained through third-party cookies for websites and anonymous identifies for mobile applications. ${ }^{6}$ There were also periods of time within our study where this data was unavailable, for reasons unknown.

[Table 1 here] 
The overall reach of the website was measured by: number of users and sessions; and source of users. We measured the engagement of all users with the website using the following indicators: bounce rates; number of page views; pages per session; session duration; and sharing. The reach and engagement of the website relative to other similar sites were measured using benchmarking data, that compared the website with other Arts and Entertainment websites (which was the most similar category of websites available) in Australia that garner 1000-4999 sessions per day.

\section{Did the website facilitate help-seeking?}

We used Google Analytics to analyse the following indicators of help-seeking: views of the 'Help a Mate' page; user pathways to and from the 'Help a Mate' page; clicks on links to helping organisations (from the entire site); and downloads of health information. Data were collated from the Google Analytics dashboard for all visits to the website during the observation period.

\section{Did the website foster conversations about suicide, mental health and help-} seeking?

Emails that were received in the observation period that were not spam, advertising or from the Man Up team, were downloaded individually in PDF format in October 2017. The PDFs of emails were imported into NVivo (V.11). Emails were grouped into conversations (emails to and fro between an emailer and the Man Up team on a single or related topics). Open-ended responses to the two open-ended survey 
questions provided between October 12 and November 20 were also imported into NVivo and analysed together with the emails.

We undertook thematic analysis of the email conversations and the two survey questions. Two of our authors (KK and MS) collaboratively developed a coding framework that captured the full range of email content with specific attention to help-seeking, mental health, and suicide content. ${ }^{8}$ They then coded $10 \%$ of emails and determined the level of agreement on coding the data. KK then coded the remaining emails using the final coding framework, consulting with MS when necessary. Emails and survey responses were coded to multiple themes as relevant.

Analysis of survey and website data by gender was not undertaken. The survey was only available to those who identified as male. It is likely that emails were received by males and females however, we were unable to reliably code emails by gender as the only information provided by emailers was their email address and their names if they signed off with one. 


\section{RESULTS}

\section{How did the website perform in terms of overall reach and engagement?}

In total, there were 54,969 unique sessions (by 43,140 new users, 11,829 by returning users) involving 103,243 page views ( 81,663 by new users, 21,580 by returning users) during the observation period. Figure 1 shows the number of users and sessions over time. The numbers of users and sessions both peaked with the screening of the first episode of the Man Up documentary on 11 October 2016. Subsequent smaller peaks in users and sessions were evident at the times of the screening of the second and third episodes (18 and 25 October) and then decreased after the screening of the third episode.

[Figure 1 here]

Table 2 shows the ten pages that were most commonly viewed by number of page views. The home page was viewed more frequently than any other page $(52,938$ views). The bounce rate for all pages was $53 \%$, with an average session duration of 3 minutes, 47 seconds, and an average of 1.9 pages viewed per session. Users spent the longest time on the pages related to each of the three episodes (13 minutes and 38 seconds to 20 minutes and 56 seconds), which may be due in part to the presence of trailers, and later episodes, on these pages. Users spent the shortest time on the 'Help a Mate' page (which provided links to helping organisations) (1 minute and 52 seconds), but this page also had the lowest exit rate indicating that many users who visited this page then went on to view other pages on the website. Following the episode-related pages, the 'Real Aussie Blokes' page was viewed by users for the longest time ( 6 minutes and 1 second). This page also had a low bounce rate and 
higher exit rate, suggesting that users spent some time on this page after looking at other pages first, and then finally exited from this page. The 'Real Aussies Bloke' page provided a set of photos and brief bios of a range of men. Users could click on a photo and this would take them to a more in-depth profile on the 'Real Aussie Blokes' website. The two most clicked men (accounting for $35.09 \%$ of clicks) were each hosts of the popular Australian YouTube channel 'Mighty Car Mods' which has over 2 million subscribers. Other commonly clicked men included: a young adult speaking about experiences with mental health, a well-known television fitness professional who is also an ex-serviceman, and a man who facilitated a workshop with teenage boys on masculinity that appeared in the documentary.

The highest bounce rate was for the 'Boys to Men' page (featuring footage from a workshop with teenage boys that appeared in the documentary) indicating that many users came directly to the site to view only that page, but they then spent an average of just over four minutes on the page.

[Table 2 here]

In total, there were 1,470 shares from the website indicating endorsement by users of website content. Of these 922 were shared to Facebook; 344 via email; and 204 to Twitter. Table 3 shows the ten most commonly shared pages. Most often shared was the homepage (887) followed by the 'About' page (131). The 'Help a Mate' page was shared 32 times. 
When compared with other similar websites in Australia the Man Up website achieved a higher average session duration ( 3 minutes, 47 seconds vs. 2 minutes, 14 seconds) and rate of new sessions (79\% vs. 63\%) but showed lower; numbers of new users $(43,140$ vs. 202,114$)$ average number of pages per session (1.9 vs 2.7$)$; and bounce rate (53\% vs $60 \%)$. These results indicate that the site engaged users to stay longer on the site on the site and received more return visits compared to other similar sites.

\section{Did the website facilitate help-seeking?}

There were 1,796 total page views of the 'Help a Mate' page (of which 1,587 were by unique users). Table 3 shows the 10 pages most commonly viewed by users immediately prior to their view of the 'Help a Mate' page. The most viewed was the 'home' page (28.98\%). Many users came directly to the 'Help a Mate' page without viewing any pages prior to it $(14.52 \%)$. The various 'Blokelore' pages accounted for $217(12.12 \%)$ of all prior page views.

[Table 3 here]

From the 1,587 unique users who viewed the 'Help a Mate' page there were 271 clicks on the links to helping organisations provided on the page (equating to a conversion rate (the rate at which users complete the desired action) of $17.08 \%$ ), and an additional 36 clicks on links to helping organisations provided elsewhere on the website (307 in total from 43,140 users, equating to a conversion rate of $0.71 \%$ ). Table 3 also shows all helping organisations links clicked. The most commonly clicked link was for the male focussed helpline service, MensLine Australia. 
There were 1,248 downloads of information from the website from various pages. 'Information about Man Up' was most frequently downloaded (446 times). Three resources that provided psychoeducation materials were also frequently downloaded: 'Men's experiences with suicidal behaviour and depression' (428 times); 'Men's help-seeking behaviour' (225 times); and 'Men's social connectedness' (149 times).

\section{Did the website foster conversations about suicide, mental health,} and help-seeking?

Four hundred and twelve emails were received during the observation period (excluding advertising, spam, and emails from Man $U p$ team staff). These emails represented 304 conversations (emails to and from emailers and the Man Up team related to an initial email from the emailer), by 300 people (as determined by their unique email address). The survey was completed 764 times. Of these completed surveys, 374 included a response to one or both of the open-ended questions.

Table 4 shows the established coding framework and the way in which the comments made in these 304 email conversations and 374 completed surveys were classified.

[Table 4 here]

\section{Suicide and mental health}

Eighty seven email conversations ( $28 \%$ of all conversations) and 83 surveys ( $22 \%$ of all surveys) related to suicide and mental health. Of these, $106(16 \%)$ included 
personal stories. These included disclosures of past suicidal thoughts and behaviours, bereavements by suicide, mental illness, family stress, and concerns for family members and friends. Quotes regarding these disclosures are not provided here given their personal and sensitive nature. Most comments did not explicitly ask for anything from the Man $U p$ team, but were simply people sharing their personal stories and experiences, and thanking the team for exploring the topic of men's mental health. Man Up team members reacted to emailed disclosures of personal stories as requests for help and provided options for help accordingly. This was not possible for survey responders as contact details were not provided.

Thirty seven emails or survey responses commented on the role of Man Up in generating community or personal awareness of mental health and suicide.

"Documentary and website are both excellent tools that can be shared among friends, in conversation at least. That's a good starting point for a topic that can be heard to bring up"

"Great job bringing this stuff from out under a rock!"

Eighteen emails or survey responses commented on actions they had taken resulting from their exposure to Man $U p$. Some emailers and survey responders spoke about how Man Up had prompted them to change their behaviour, including the way they interacted with their children and other people. 
"My son woke up grumpy, so instead of telling him to knock it off and just get on with it, I let him have his rant and carry on and once he was quiet and he had walked our dogs, I asked him to start watching Man Up. So thank you - your show has changed my life."

"I used the content to talk to the offenders in my group in maximum security. As I finished my talk to these vulnerable men, there was a knock at the door to advise one offender his little brother had committed suicide. It was devastating. Thanks for enabling me to talk with men."

\section{Help-seeking}

Thirty emailers made specific requests for help. Twenty five requests were for information or for a speaker for a local community group (such as a self-help, professional, workplace, or school group). Emailers specifically made reference to a segment of the documentary that featured Tom Harkin, (an expert facilitator who leads personal development sessions that examine masculinity) challenging the thinking of a group of high school boys.

"We are looking into getting some sort of program into our school next year. Can you provide any assistance please? We have seen the documentary and if your people would be able to present this to our Y9 boys, that would be awesome."

"I am wondering who I might be able to get in touch with Tom Harkin. I saw him on the Man Up series and think he would be a wonderful speaker for a men's program I run for men bereaved by suicide." 
Twelve emails requested support for emailers themselves or for others. These emails generally provided details of a problem faced, followed by a request for services, information, advice or non-specific help.

"What more can I do to help my husband?"

"Can you help me at all with information of who or where I can turn to and find real help?"

Whilst survey responses didn't include specific requests for help, 16 survey responses commented on help-seeking. People described help-seeking they were currently undertaking or how Man $U p$ had inspired help-seeking for themselves or others.

"The people, the time, the hard work you have done, has really opened my eyes to the help that is available"

A few responses commented on negative experiences related to help-seeking.

"The worst thing I ever did was admit to my problem"

The majority of the email conversations and surveys provided positive feedback about Man Up (435 (64\%)). Ninety one emails requested to be further involved in the Man Up initiative, through collaboration or personal assistance. Many emails and 
survey responses $(65,10 \%)$ provided suggestions for improvement, and a small number $(31,6 \%)$ provided negative feedback. As shown in Table 4, 19 emailers and 12 survey respondents provided negative comments. The most common negative comments (by 9 emailers and 3 survey respondents) related to the way in which men were portrayed in the documentary.

"Another useless project starting with the premise that masculinity is toxic or fundamentally flawed.... let's just ignore all the positive masculine traits and focus on the negative"

"It saddens me to see the current trend of portraying men as boofheads and stupid men in beer ads" 


\section{DISCUSSION}

This paper assesses the Man Up website's effectiveness in engaging with people, facilitating help-seeking, and stimulating conversations about suicide, mental health and help-seeking.

Google Analytics data revealed that the website reached 43,140 users. Users engaged well with the website with a high rate of average session duration and lower bounce rate compared to similar websites. There were 1,470 shares from the site indicating strong endorsement of content. There was evidence of help-seeking by website users: 1,791 page views of the 'Help a Mate' page; 307 outbound clicks to helping organisations (equating to a conversion rate of $17.08 \%$ from the 'Help a Mate' page and $0.71 \%$ from the site more broadly); and 802 downloads of psychoeducation materials. There is little benchmarking data available regarding conversion rates and sharing for mental health, or health, websites. Average conversion rates for websites across different industries range from 3 to $13 \% .{ }^{9}$ Our understanding of the impact of Man Up on help-seeking could have been further enhanced by exploring data related to contacts made with helping organisations during the initiative.

Aside from the home pages, the 'Blokelore' pages, which offered light-hearted and comical reflections on different aspects of masculinity, were commonly viewed immediately prior to the 'Help a Mate' page. There was considerable discussion of suicide and mental health via email and in survey responses, with many disclosures of personal experiences and also many people sharing information about activities being undertaken in the community. Help-seeking was evident within disclosures of 
personal life experiences and there were also some explicit requests for help. The fact that so many people made unsolicited contact and shared such personal reactions and experiences speaks strongly to the degree to which Man Up resonated with viewers and stirred them to take some action. In sum, the three data sources explored here (Google Analytics, surveys responses, and email content) together indicate that Man Up was successful in engaging people in the key messages of mental health and suicide prevention and acted to prompt help-seeking, whether that be through clicks on website links to help-seeking organisations, downloads of psychoeducational materials, or emails to Man Up requesting help.

We were unable to analyse Google Analytics data by gender and age. Neither could we analyse our survey or email data by gender, as only those identified as male were able to complete the survey and gender was not supplied by emailers. Our findings would have been strengthened by an exploration of patterns of use, and help-seeking, by demographic variables, which could then enable specific tailoring of website content.

Google Analytics is a valuable, and relatively easy to use, tool that can be used to gauge the success of web based public health interventions and tailor interventions in real time to maximise future success. Website evaluation using the methods presented here can be used in an iterative way to inform the ongoing development of the website. For instance, findings can be used to improve the effectiveness of the website in facilitating help-seeking in real time. Information available for download could be increased and popular articles could be moved to a more prominent position on the website. Light-hearted comical content could be increased and highlighted as 
it worked well to direct users to help-seeking. A website evaluation can also provide a window into broader public opinion and response. The level of engagement with the website and the high level of positive feedback provided via email and survey is an important finding, given that any media-based intervention can only be effective if people are willing to view it.

The Man Up initiative had a strong focus on the interplay between masculinity and suicide. This focus on masculinity in relation to behaviour change is relatively new. Positive changes in health behaviours related to violence and the spread of HIV have been previously demonstrated through the use of interventions that target masculine norms. ${ }^{10}$ However, to the best of our knowledge, this is the first time that such an intervention has been able to demonstrate an impact on mental health related outcomes. The impact of Man Up is further evidenced by findings from our other evaluation activities, including a randomised controlled trial and a social media evaluation. ${ }^{11-15}$ The positive impact on help-seeking behaviour is an extremely important finding given that men report more negative attitudes towards helpseeking for mental health concerns compared to women, and also seek help at lower rates than women, even when they have similar levels of psychological distress. ${ }^{16-18}$ Increasing help-seeking has been cited as one of the key challenges in men's health. ${ }^{19}$

The findings here highlight the value of complementing a media-based public health intervention with other avenues for engagement. A recent review of suicide prevention campaigns similarly suggested that campaigns are most effective if they are conducted across multiple media platforms. ${ }^{20}$ Our paper demonstrates the 
mechanisms by which effective health outcomes can be achieved by a multi-level media-based public health intervention: a social media campaign directs people to watch a documentary which in turn prompts people to visit a website (and also to return to the social media campaign), the website then provides individuals with further information and opportunities for help-seeking. Each element promotes the key messages of the initiative, but together the strength of the message is amplified and, in this case, individuals are led through a pathway towards help-seeking.

The Man Up initiative continued to be active throughout 2017 and 2018. The documentary was screened a further three times by the $\mathrm{ABC}$ and remains available on their catch-up TV service, and on the Movember Foundation's website. The Man $U p$ website is still available and social media activities have continued, albeit in a reduced way. It is likely that these activities have further reinforced the messages of Man Up and introduced the initiative to new people. 


\section{CONCLUSION}

In summary, the Google Analytics, email and survey data demonstrated that the website provided an important opportunity for people to further engage with Man $U p$ and undertake help-seeking. Entertainment can be successfully coupled with sensitive health topics to encourage positive health behaviours. Media-based public health interventions offer enormous potential to provide suicide prevention interventions to men given their reluctance to seek help.

Ethics approval: The study reported in this paper has received ethics approval from The University of Melbourne's Human Ethics Sub-Committee (ID: 1647844.1) 


\section{CONFLICTS OF INTEREST}

The authors declare no conflicts of interest 


\section{REFERENCES}

1. Pirkis J, Mok K, Robinson J. Suicide and the newer media: the good, the bad, and the googly. In: Niederkrotenthaler T, Stack S, eds. Media and Suicide. New York: Transaction Publishers 2017.

2. Australian Bureau of Statistics. 3303.0 - Causes of Death, Australia, 2016 Canberra2017 [Available from: http://www.abs.gov.au.

3. Pirkis J, Spittal M, Keogh L, et al. Masculinity and suicidal thinking. Social Psychiatry \& Psychiatric Epidemiology 2016 doi: 10.1007/s00127-0161324-2

4. Wong YJ, Ringo Ho M-H, Wang S-Y, et al. Meta-analyses of the relationship between conformity to masculine norms and mental health-related outcomes. Journal of Counseling Psychology 2017;64(1):80-93. doi: $10.1037 / \mathrm{cou} 0000176$

5. Ajzen I. The theory of planned behavior. Organizational Behavior and Human Decision Processes 1991;50:179-211. doi: 10.1016/0749-5978(91)90020$\mathrm{T}$

6. Google. Google Analytics Help 2017 [Available from: https://support.google.com/analytics accessed 11 Sept 2017.

7. Crutzen R, Roosjen JL, Poleman J. Using Google Analytics as a process evaluation method for Internet-delivered interventions: an example on sexual health. . Health Promotion International 2012;28(1):36-42. doi: 10.1093/heapro/das008

8. Green J, Thorogood N. Qualitative Methods for Health Research. Los Angeles, California: Sage 2014.

9. Sharma R. What is a good conversion rate? https://blog.ladder.io/conversionrate/: Ladder, 2018.

10. Dworkin S, Fleming P, Colvin C. The promises and limitations of gendertransformative programming with men: critical reflections from the field. Culture, Health \& Sexuality 2015;17(sup2):128-43. doi: $10.1080 / 13691058.2015 .1035751$

11. King K, Schlichthorst M, Reifels L, et al. Can a documentary increase helpseeking intentions in men? A randomised controlled trial. Journal of Epidemiology and Community Health 2018;72(1):92-98. doi: 10.1136/jech-2017-209502

12. King K, Schlichthorst M, Reifels L, et al. Impacts of a Documentary about Masculinity and Men's Health. American Journal of Men's Health 2018;12(5):1604-14. doi: 10.1177/1557988318777927

13. King K, Schlichthorst M, Keogh L, et al. Can Watching a Television Documentary Change the Way Men View Masculinity? The Journal of Men's Studies;2018:1060826518815909. doi: $10.1177 / 1060826518815909$

14. Schlichthorst M, King K, Spittal M, et al. Using a television documentary to prevent suicide in men and boys. AUSTRALASIAN PSYCHIATRY 2018;26(2):160-65. doi: 10.1177/1039856217749022

15. Schlichthorst $M$, King K, Turnure J, et al. Influencing the conversation about masculinity and suicide: Using Twitter data in the evaluation of the 'Man Up' multi-media campaign. JMIR Mental Health 2018;5(1):e14. doi: 10.2196/mental.9120 
16. Siedler ZE, Dawes AJ, Rice SM, et al. The role of masculinity in men's helpseeking for depression: a systematic review. Clinical Psychology Review 2016;49:106-18. doi: 10.1016/j.cpr.2016.09.002

17. MacKenzie C, Gekoski W, Knox V. Age, gender, and the underutilization of mental health services: the influence of help-seeking attitudes. Aging \& Mental Health 2006;10(6):574-82. doi: 10.1080/13607860600641200

18. Kapur N, Hunt I, Lunt M, et al. Primary care consultation predictors in men and women: a cohort study. British Journal of General Practice 2005;55(511):108-13.

19. Galdas P, Cheater F, Marshall P. Men and health help-seeking behaviour: Literature review. Journal of Advanced Nursing 2005;49(6):616-23. doi: 10.1111/j.1365-2648.2004.03331.x

20. Torok M, Calear A, Shand F, et al. A systematic review of mass media campaigns for suicide prevention: Understanding their efficacy and the mechanisms needed for successful behavioral and literacy change. Suicide \& Life-Threatening Behavior 2017;47(6):672-87. doi: 10.1111/sltb.12323 


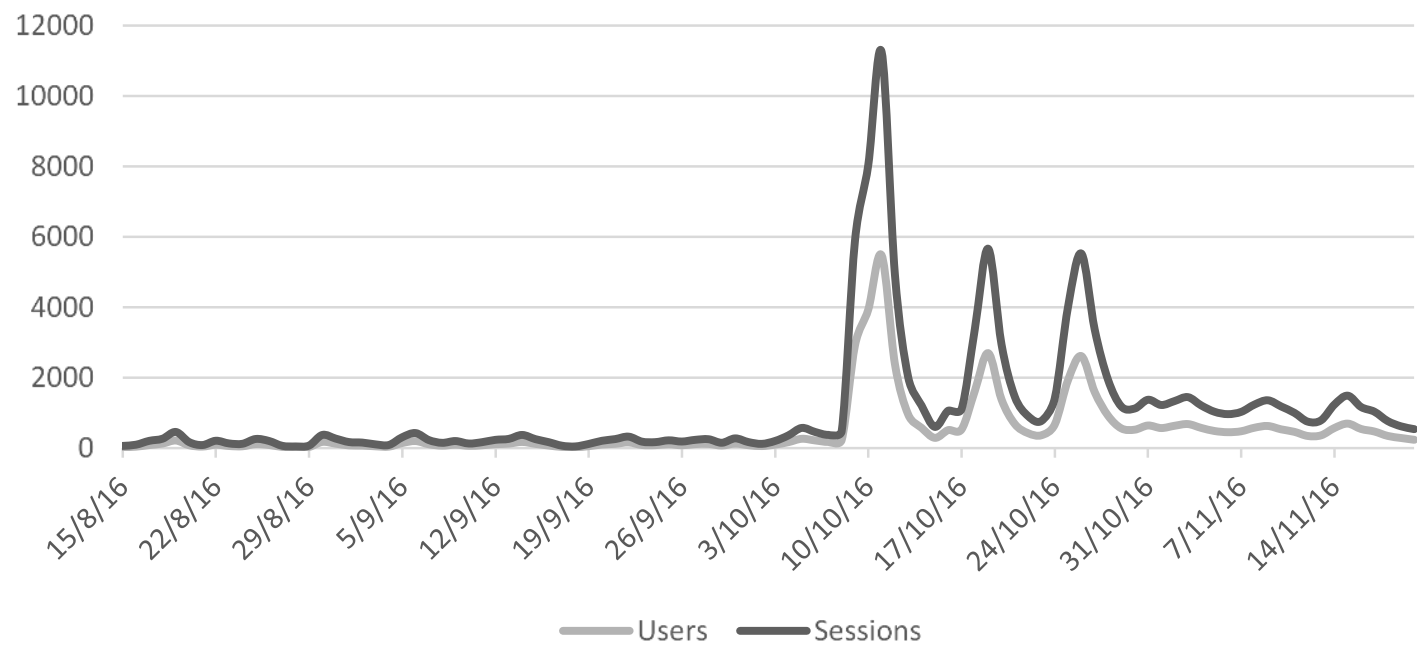

Figure 1: Number of users and sessions over time 
Table 1. Definition and operationalisation of Google analytic terms. ${ }^{5}$

\begin{tabular}{|c|c|c|}
\hline Term & Definition & Operationalisation \\
\hline User & $\begin{array}{l}\text { A person who access } \\
\text { the website. }\end{array}$ & $\begin{array}{l}\text { A user is identified by a unique, } \\
\text { randomly generated string that is } \\
\text { stored in the browsers cookies. }\end{array}$ \\
\hline Country & $\begin{array}{l}\text { Country that user is } \\
\text { based in. }\end{array}$ & $\begin{array}{l}\text { Geographical information is } \\
\text { derived from the IP address of } \\
\text { the user that provides an } \\
\text { approximation of the location of } \\
\text { the user. }\end{array}$ \\
\hline Session & $\begin{array}{l}\text { The period of time a } \\
\text { user is active on the } \\
\text { website. }\end{array}$ & $\begin{array}{l}\text { If a user is inactive for } 30 \\
\text { minutes or more, any future } \\
\text { activity is attributed to a new } \\
\text { session. Users that leave the site } \\
\text { and return within } 30 \text { minutes are } \\
\text { counted as part of the original } \\
\text { session. }\end{array}$ \\
\hline Pageview & $\begin{array}{l}\text { A single view of a } \\
\text { website page }\end{array}$ & $\begin{array}{l}\text { An instance of a page being } \\
\text { loaded (or reloaded) in a } \\
\text { browser. Pageviews is a metric } \\
\text { defined as the total number of } \\
\text { pages viewed. }\end{array}$ \\
\hline Sources & $\begin{array}{l}\text { The origin of website } \\
\text { traffic }\end{array}$ & $\begin{array}{l}\text { Sources are: organic search; } \\
\text { social; direct; or referral. }\end{array}$ \\
\hline $\begin{array}{l}\text { Organic } \\
\text { search }\end{array}$ & $\begin{array}{l}\text { Traffic received from } \\
\text { search engines }\end{array}$ & $\begin{array}{l}\text { The user has used a search } \\
\text { engine (Google, bing etc.) to } \\
\text { find the site. }\end{array}$ \\
\hline Social & $\begin{array}{l}\text { Traffic received from a } \\
\text { link in social media } \\
\text { channels }\end{array}$ & $\begin{array}{l}\text { The user has clicked on a link in } \\
\text { a social media channels } \\
\text { (Facebook, Twitter, Instagram } \\
\text { etc.) }\end{array}$ \\
\hline Direct & $\begin{array}{l}\text { Traffic received without } \\
\text { searching. }\end{array}$ & $\begin{array}{l}\text { The website URL has been typed } \\
\text { directly into a user's browser. }\end{array}$ \\
\hline Referral & $\begin{array}{l}\text { Traffic received from } \\
\text { other external websites. }\end{array}$ & $\begin{array}{l}\text { The user has clicked on a link to } \\
\text { the website from another } \\
\text { website. }\end{array}$ \\
\hline Bounce & $\begin{array}{l}\text { A session or user that } \\
\text { exits after viewing only } \\
\text { one page. }\end{array}$ & $\begin{array}{l}\text { For a particular page, the bounce } \\
\text { rate is the percentage of sessions } \\
\text { that comprised only that page } \\
\text { view. }\end{array}$ \\
\hline Exit & $\begin{array}{l}\text { The number of sessions } \\
\text { or users that left the } \\
\text { website. }\end{array}$ & $\begin{array}{l}\text { For a particular page, the exit } \\
\text { rate is the percentage of } \\
\text { pageviews that were the last in } \\
\text { the session. }\end{array}$ \\
\hline
\end{tabular}


Table 1 . Top 10 page views

\begin{tabular}{llllll}
\hline Page & $\begin{array}{l}\text { No. } \\
\text { Page } \\
\text { views }\end{array}$ & \% & $\begin{array}{l}\text { Avg. Time } \\
\text { on Page } \\
\text { (min:sec) }\end{array}$ & $\begin{array}{l}\text { Bounce } \\
\text { Rate \% }\end{array}$ & $\begin{array}{l}\text { Exit } \\
\text { rate } \\
\text { \% }\end{array}$ \\
\hline Home page & 52938 & 51.28 & $2: 24$ & 53.44 & 57.78 \\
About & 7894 & 7.65 & $2: 51$ & 51.42 & 54.42 \\
Episode 1 & 6131 & 5.94 & $13: 38$ & 50.27 & 57.89 \\
Episode 2 & 3319 & 3.21 & $15: 33$ & 39.09 & 56.43 \\
Real Aussie Blokes & 2821 & 2.73 & $6: 01$ & 35.66 & 65.47 \\
Boys To Men & 2795 & 2.71 & $4: 07$ & 63.76 & 53.92 \\
Survey & 2000 & 1.94 & $3: 45$ & 53.22 & 48.15 \\
Help A Mate & 1796 & 1.74 & $1: 52$ & 60.00 & 38.08 \\
Episode 3 & 1743 & 1.69 & $20: 56$ & 36.01 & 53.41 \\
The Stats & 1510 & 1.46 & $2: 57$ & 65.54 & 40.53 \\
TOTAL & 103243 & 100.00 & $3: 47$ & 52.91 & 52.37 \\
\hline
\end{tabular}


Table 2. Number of page shares, page views prior to 'Help a Mate' and outbound clicks to helping organisations

\begin{tabular}{|c|c|c|}
\hline Page & $\begin{array}{l}\text { No. page } \\
\text { shares }\end{array}$ & $\%$ \\
\hline Home page & 887 & 60.34 \\
\hline About & 131 & 8.91 \\
\hline Episode 1 & 58 & 3.95 \\
\hline Episode 2 & 42 & 2.86 \\
\hline Blokelore - Boys to men & 36 & 2.45 \\
\hline Help a mate & 32 & 2.18 \\
\hline TV blog & 29 & 1.97 \\
\hline Survey & 14 & 0.95 \\
\hline Blokelore -Men love bush & 14 & 0.95 \\
\hline Contact & 24 & 1.63 \\
\hline Total & 1,470 & 100 \\
\hline Page & $\begin{array}{l}\text { No. views prior } \\
\text { to 'Help a } \\
\text { Mate' }\end{array}$ & $\%$ \\
\hline Home & 519 & 28.98 \\
\hline Entrance* & 260 & 14.52 \\
\hline About & 139 & 7.76 \\
\hline Blokelore - Boys to men & 92 & 5.14 \\
\hline Survey & 61 & 3.41 \\
\hline Blokelore - The mate test & 54 & 3.02 \\
\hline The facts - Help seeking behaviour & 42 & 2.35 \\
\hline The facts - The stats & 43 & 2.40 \\
\hline Blokelore & 36 & 2.01 \\
\hline Blokelore - How big is your organ & 35 & 1.95 \\
\hline Page link & $\begin{array}{l}\text { No. outbound } \\
\text { clicks }\end{array}$ & $\%$ \\
\hline MensLine Australia & 63 & 20.52 \\
\hline beyondblue & 45 & 14.66 \\
\hline Black Dog Institute & 42 & 13.68 \\
\hline Reach Out & 29 & 9.45 \\
\hline Mates in Construction & 28 & 9.12 \\
\hline Headspace & 23 & 7.49 \\
\hline Lifeline & 22 & 7.17 \\
\hline Kids Helpline & 13 & 4.23 \\
\hline Mens Shed & 13 & 4.23 \\
\hline Mates 4 Mates & 13 & 4.23 \\
\hline Sane & 10 & 3.26 \\
\hline $\begin{array}{l}\text { Veterans and veterans family counselling } \\
\text { service }\end{array}$ & 6 & 1.95 \\
\hline Total & 307 & 100 \\
\hline
\end{tabular}

* User entered the website at this page 
Table 3. Number of emails and survey respondents commenting on each theme

\begin{tabular}{|c|c|c|c|c|}
\hline $\begin{array}{l}\text { First level } \\
\text { themes }\end{array}$ & $\begin{array}{l}\text { Second level } \\
\text { themes }\end{array}$ & $\begin{array}{l}\text { No. } \\
\text { emails } \\
(n= \\
304)\end{array}$ & $\begin{array}{l}\text { No. survey } \\
\text { respondents } \\
(n=374)\end{array}$ & $\begin{array}{l}\text { Total } \\
(N= \\
678)\end{array}$ \\
\hline \multirow{4}{*}{$\begin{array}{l}\text { Suicide and } \\
\text { mental } \\
\text { health }\end{array}$} & Personal stories & 66 & 40 & 106 \\
\hline & Action & 7 & 11 & 18 \\
\hline & Raising awareness & 20 & 18 & 38 \\
\hline & $\begin{array}{l}\text { Other suicide and } \\
\text { mental health }\end{array}$ & 0 & 16 & 16 \\
\hline \multirow{3}{*}{$\begin{array}{l}\text { Help- } \\
\text { seeking }\end{array}$} & For self & 4 & 10 & 14 \\
\hline & For others & 10 & 6 & 16 \\
\hline & For groups of people & 16 & 0 & 16 \\
\hline \multirow{3}{*}{$\begin{array}{l}\text { Positive } \\
\text { feedback }\end{array}$} & General positive & 127 & 145 & 272 \\
\hline & Request to be involved & 91 & 3 & 94 \\
\hline & $\begin{array}{l}\text { Request to obtain } \\
\text { documentary }\end{array}$ & 61 & 8 & 69 \\
\hline \multirow{2}{*}{$\begin{array}{l}\text { Negative } \\
\text { feedback }\end{array}$} & Portrayal of men & 9 & 3 & 12 \\
\hline & $\begin{array}{l}\text { Other negative } \\
\text { comments }\end{array}$ & 10 & 9 & 19 \\
\hline \multirow[t]{4}{*}{ Suggestions } & The role of women & 7 & 0 & 7 \\
\hline & $\begin{array}{l}\text { Focus on specific } \\
\text { groups }\end{array}$ & 3 & 2 & 5 \\
\hline & Providing resources & 17 & 3 & 20 \\
\hline & Other suggestions & 19 & 14 & 33 \\
\hline
\end{tabular}

